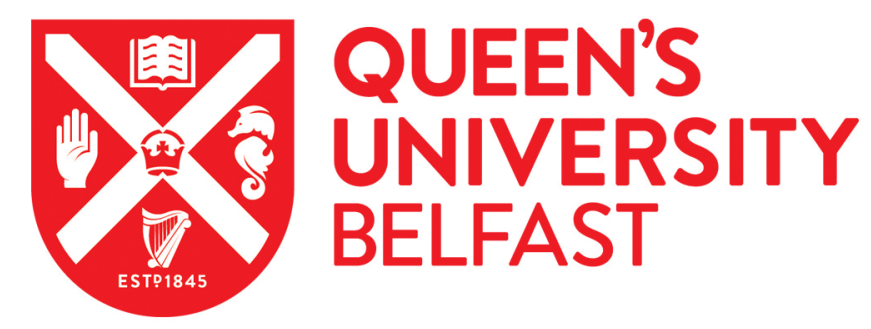

\title{
Face Masks and Cough Etiquette Reduce the Cough Aerosol Concentration of Pseudomonas aeruginosa in People with Cystic
} Fibrosis

Wood, M. E., Stockwell, R. E., Johnson, G. R., Ramsay, K. A., Sherrard, L. J., Jabbour, N., Ballard, E., O'Rourke, P., Kidd, T. J., Wainwright, C. E., Knibbs, L. D., Sly, P. D., Morawska, L., \& Bell, S. C. (2017). Face Masks and Cough Etiquette Reduce the Cough Aerosol Concentration of Pseudomonas aeruginosa in People with Cystic Fibrosis. American Journal of Respiratory and Critical Care Medicine, 197(3), 1-34.

https://doi.org/10.1164/rccm.201707-1457OC

Published in:

American Journal of Respiratory and Critical Care Medicine

Document Version:

Peer reviewed version

Queen's University Belfast - Research Portal:

Link to publication record in Queen's University Belfast Research Portal

Publisher rights

Copyright 2017 American Thoracic Society. This work is made available online in accordance with the publisher's policies. Please refer to any applicable terms of use of the publisher.

\section{General rights}

Copyright for the publications made accessible via the Queen's University Belfast Research Portal is retained by the author(s) and / or other copyright owners and it is a condition of accessing these publications that users recognise and abide by the legal requirements associated with these rights.

\section{Take down policy}

The Research Portal is Queen's institutional repository that provides access to Queen's research output. Every effort has been made to ensure that content in the Research Portal does not infringe any person's rights, or applicable UK laws. If you discover content in the Research Portal that you believe breaches copyright or violates any law, please contact openaccess@qub.ac.uk. 
1 Face masks and cough etiquette reduce the cough aerosol concentration of Pseudomonas

4 Michelle E Wood*1,2,3, Rebecca E Stockwell ${ }^{1,3}$, Graham R Johnson ${ }^{4}$, Kay A Ramsay ${ }^{1,3}$, Laura

5 J Sherrard $^{1,5}$, Nassib Jabbour ${ }^{4}$, Emma Ballard ${ }^{6}$, Peter O’Rourke ${ }^{6}$, Timothy J Kidd ${ }^{1,7,8}$, Claire

6 E Wainwright ${ }^{3,8,9}$, Luke D Knibbs ${ }^{10}$, Peter D Sly ${ }^{3,8}$ Lidia Morawska $^{4}$, Scott C Bell ${ }^{1,2,3}$.

$7 \quad{ }^{1}$ Lung Bacteria Group, QIMR Berghofer Medical Research Institute, QLD 4006, Australia.

$8 \quad{ }^{2}$ Adult Cystic Fibrosis Centre, The Prince Charles Hospital, Brisbane, QLD 4032, Australia.

$9 \quad{ }^{3}$ Faculty of Medicine, The University of Queensland, Brisbane, QLD 4027, Australia.

$10{ }^{4}$ International Laboratory for Air Quality and Health, Queensland University of Technology,

11 Brisbane QLD 4000, Australia

12 55chool of Pharmacy, Queen's University Belfast, Belfast BT9 7BL, United Kingdom

$13{ }^{6}$ Statistical Support Group, QIMR Berghofer Medical Research Institute, Brisbane, QLD 14 4006, Australia.

$15{ }^{7}$ School of Chemistry and Biomolecular Sciences, The University of Queensland, Brisbane, 16 QLD 4027, Australia

$17{ }^{8}$ Child Health Research Centre, The University of Queensland, South Brisbane, QLD 4101, 18 Australia.

19 '9ady Cilento Children's Hospital, South Brisbane, QLD 4101, Australia

$20{ }^{10}$ School of Public Health, The University of Queensland, Herston, QLD 4006, Australia 


\section{EMAIL:}

22 michelle.wood2@health.qld.gov.au

23 rebecca.stockwell@qimrberghofer.edu.au

24 g.johnson@qut.edu.au

25 k.ramsay@uq.edu.au

26 1sherrard03@qub.ac.uk

27 n.jabbour@qut.edu.au

28 emma.ballard@qimrberghofer.edu.au

29 peter.orourke@qimrberghofer.edu.au

30 t.m.kidd@uq.edu.au

31 claire.wainwright@health.qld.gov.au

32 1.knibbs@uq.edu.au

33 p.sly@uq.edu.au

34 1.morawska@qut.edu.au

35 scott.bell@qimrberghofer.edu.au

37 *Corresponding author. Adult Cystic Fibrosis Centre, The Prince Charles Hospital, 627

38 Rode Road, Brisbane QLD 4032, Australia.

39 Tel: +61 73139 4193; Fax: +61 73139 5630; Email: michelle.wood2@health.qld.gov.au 
Author contributions: G.R.J, L.D.K, T.J.K, L.M and S.C.B conceived and designed the experiment and S.C.B, T.J.K, L.M., C.E.W and P.D.S. led the funding applications. M.E.W, R.E.S, G.R.J and N.J conducted the cough studies and acquired the data. R.E.S, K.A.R and L.J.S performed microbiological analysis. P.O'R and E.B led the data analysis. M.E.W and S.C.B oversaw the overall study, provide overall responsibility for the data and wrote the manuscript, with input from all co-authors.

Funding support: The study was funded by grants from Cystic Fibrosis Foundation Therapeutics USA (BELL14AO) and The Prince Charles Hospital Foundation (MS2014-20). T.J.K. acknowledges National Health and Medical Research Council (NHMRC) Early Career (GNT1088448) and ERS-EU RESPIRE2 Marie Sklodowska-Curie Postdoctoral Research (\#4571-2013) Fellowship support. L.D.K. acknowledges an NHMRC Early Career Fellowship (APP1036620)

List ONE descriptor number that best classifies the subject of your manuscript: 9.17

Cystic Fibrosis: Translational \& Clinical Studies

Total word count for the body of the manuscript $=3751$

\section{At a Glance Commentary.}

Scientific Knowledge on the Subject: Pseudomonas aeruginosa is the dominant airways infection in people with cystic fibrosis (CF). People can harbor genetically indistinguishable strains of $P$. aeruginosa, which suggests that cross infection may be an important mode of transmission, although the mechanisms are not well understand. Droplet nuclei containing $P$. 
63 aeruginosa produced during coughing can remain viable for extended periods, raising the 64 possibility of airborne transmission. The CF Foundation recommends that people with CF 65 wear a surgical mask in communal areas to reduce pathogen acquisition and transmission.

66 What This Study Adds to the Field: This comparative observational study demonstrated 67 that surgical masks and the N95 masks are effective in reducing aerosols containing viable $P$. 68 aeruginosa 2-metres from source during coughing in people with CF. Short-term use of face 69 masks was well tolerated in people with CF lung disease, with the surgical mask rated more 70 comfortable than the N95 mask. Cough etiquette reduced viable aerosols to a lesser extent 71 than face masks.

73 This article has an online data supplement, which is accessible from this issue's table of 74 content online at www.atsjournals.org 
78 Rationale: People with cystic fibrosis (CF) generate Pseudomonas aeruginosa in droplet 79 nuclei during coughing. The use of surgical masks has been recommended in healthcare settings to minimise pathogen transmission between CF patients.

81 Objective: To determine if face masks and cough etiquette reduce viable $P$. aeruginosa aerosolised during cough.

83 Methods: Twenty-five adults with $\mathrm{CF}$ and chronic $P$. aeruginosa infection were recruited. 84 Participants performed six talking and coughing maneuvers, with or without face masks (surgical and N95) and hand covering the mouth when coughing (cough etiquette) in an aerosol-sampling device. An Andersen Impactor sampled the aerosol at 2-meters from each participant. Quantitative sputum and aerosol bacterial cultures were performed and participants rated the mask comfort levels during the cough maneuvers.

Measurements and Main Results: During uncovered coughing (reference maneuver), 19/25 (76\%) participants produced aerosols containing $P$. aeruginosa, with a positive correlation

91 found between sputum $P$. aeruginosa concentration $(\mathrm{CFU} / \mathrm{mL})$ and aerosol $P$. aeruginosa

92 CFUs. There was a reduction in aerosol $P$. aeruginosa load during coughing with surgical mask, coughing with N95 mask and cough etiquette compared with uncovered coughing $(p<0.001)$. A similar reduction in total CFUs was observed for both masks during coughing, yet participants rated surgical masks more comfortable $(p=0.013)$. Cough etiquette provided approximately half the reduction of viable aerosols of the mask interventions during voluntary cough. Talking was a low viable aerosol producing activity. 
98 Conclusions: Face masks reduce cough generated P. aeruginosa aerosols, with the surgical 99 mask providing enhanced comfort. Cough etiquette was less effective at reducing viable 100 aerosols.

101 Word count $=248$

102 Key words: cystic fibrosis; infection control; surgical mask, N95 mask; cough etiquette

103

104

105

106

107

108

109

110

111

112

113

114

115

116 
Pseudomonas aeruginosa is the dominant pathogen in the airways of people with cystic fibrosis (CF), with a prevalence of up to $70 \%$ in adults (1-3). Chronic $P$. aeruginosa infection is associated with pulmonary function decline, increased exacerbations, poorer health-related quality of life and reduced survival (4-6). Studies have demonstrated that unrelated people with CF can harbor genetically indistinguishable strains, suggesting person-to-person spread of $P$. aeruginosa (7-11). Consequently, CF infection control guidelines published in 2003 sought to minimise potential contact and droplet transmission of pathogens and recommended cohort segregation according to microbiological status, single room inpatient accommodation and a separation distance of 1-meter between people with CF (12). Although such measures are thought to have contributed to a reduction in epidemic P. aeruginosa (13) and Burkholderia cenocepacia strain acquisition (14), cross infection with CF pathogens has continued $(11,15,16)$.

Airborne transmission of $P$. aeruginosa was first suggested as a possible mode of crossinfection by studies that assessed environmental air contamination in CF clinical care settings (17) and cough aerosols from people with CF (18). Particle size diameter is used to categorize respiratory aerosols into droplets $(>5 \mu \mathrm{m})$ and droplet nuclei $(\leq 5 \mu \mathrm{m})$; with the latter a consequence of droplet evaporation and capable of airborne transmission (19). Our earlier work demonstrated that cough generated droplet nuclei containing $P$. aeruginosa in the respirable size range remained viable for up to 45-minutes and were detected up to 4-meters from the source (20). The updated CF infection control guidelines published in 2014 recommended a separation distance of 2-meters and included the specific recommendation for people with CF to wear a surgical mask in communal areas of healthcare facilities (21). 
140 Face masks and cough etiquette (i.e. coughing into the hand or arm) are strategies that may 141 interrupt aerosol dispersal. The primary role of the surgical mask is to prevent contamination 142 of the environment by infectious droplets. The relatively low efficiency capture of aerosols, 143 particularly during cough, and incomplete seal may allow particles to escape around the 144 perimeter (22). The N95 mask provides inward protection from inhaled airborne pathogens, and it is reasonable to also expect limitation of aerosolised infectious material generated by the wearer. To date there is limited evidence of outward protection by surgical and N95 masks and the tolerability of these interventions has not been widely studied in patients with lung disease. Therefore, this study aimed to determine and compare the effectiveness and comfort of two commonly utilized face masks and cough etiquette on dispersal of aerosolised P. aeruginosa during talking and coughing in adults with CF. Some of the results of this study have been previously reported in the form of an abstract (23).

\section{METHODS}

154 See online supplement for additional details.

Participants: Participants $(n=25)$ were recruited from The Prince Charles Hospital (TPCH) Adult Cystic Fibrosis Centre (ACFC), Brisbane, Australia in 2015. Eligible participants had a confirmed $\mathrm{CF}$ diagnosis, aged $\geq 18$ years and chronic $P$. aeruginosa infection as determined by modified Leed's criteria (3). Exclusion criteria comprised recent haemoptysis $(>50 \mathrm{ml})$, pneumothorax, pregnancy and cough syncope. Written, informed participant consent was obtained and the study was approved by the local ethics committee.

Aerosol sampling system: Using a validated, closed wind-tunnel system, viable aerosols were collected at 2-meters from participants (24); the sampling distance was defined in 

recommending 2-meters between-person separation (21). Seated participants positioned their head within the tunnel with a weighted material cover rested over the shoulders and a slight positive tunnel pressure to prevent room air contamination (20).

Aerosol sampling protocol: Participants completed six maneuvers on a single day: 1) talking; 2) talking wearing a tied surgical mask (Kimberley-Clark TECNOL Fluidshield FogFree Surgical Mask, Georgia, USA); 3) uncovered coughing (reference maneuver); 4) coughing wearing a tied surgical mask; 5) coughing wearing an N95 mask (Kimberley-Clark N95 Particulate Filter Respirator, NSW, Australia); 6) coughing with their hand covering their mouth (cough etiquette). The testing order of the uncovered cough maneuver, coughing wearing a surgical mask and coughing wearing an N95 mask were randomized to minimize potential bias in aerosol production resulting from fatigue and airway clearance with repeated coughing (25). For logistical reasons, the cough etiquette test was the final maneuver performed and participants were asked to adopt their usual mouth covering technique (a glove was worn on the cough covering hand to minimize microbial dispersal from skin). Participants rested for $\geq 20$ minutes between each maneuver. Face masks were sized and applied by a trained healthcare professional.

Within the tunnel each participant completed 2-minutes of tidal breathing in high-efficiency particulate air (HEPA) filtered air to washout residual room air, then 5-minutes of the respective maneuver (talk/cough) during which aerosols were continuously sampled through a six-stage Andersen Impactor (Thermo Scientific ${ }^{\mathrm{TM}}$ ), followed by 2-minutes of tidal breathing. Participants then completed a 5-point comfort rating score (26) and provided comments regarding mask wear during coughing. Masks were weighed before and immediately after each maneuver. 
Clinical Measurements: Demographic and clinical measurements were recorded, including: age, gender, body mass index (BMI) and intravenous antibiotic use in the week prior. A sputum sample was collected on the study day. Spirometry (FEV 1 and FVC) was performed according to ATS/ERS standards (27) and the Global Lung Index (GLI) predicted scale (28) applied.

Microbiology: Standardized qualitative and quantitative sputum cultures were performed, as previously described (20). P. aeruginosa identification was confirmed by oxidase testing, $42^{\circ} \mathrm{C}$ growth and MALDI-TOF mass spectrometry. $P$. aeruginosa genotyping was undertaken using the Sequenom iPLEX20SNP assay, as previously described (29).

Statistical analysis: A sample size calculation based on our earlier work (20) suggested 21 patients were required to demonstrate a 40 percentage point reduction in the presence or absence of $P$. aeruginosa with $80 \%$ power with a two-tailed $p=0.05$. Therefore, 25 patients with CF and chronic $P$. aeruginosa were enrolled, allowing for $10-15 \%$ dropout to achieve a sample size of 21. SPSS version 22 was used for statistical analysis. Categorical variable associations were examined using Fisher's Exact test. Continuous variables describing participant characteristics were examined using a Student t-test. Clinical and demographic variables were compared with the log transformed total $P$. aeruginosa aerosol colony forming units (CFUs) in the uncovered cough maneuver using a Pearson correlation test. The paired ttest based on log transformed CFU was used to compare each intervention maneuver with the reference maneuver (uncovered coughing). Results were stratified by the level of aerosol production as follows: participants were classed as high, low or nil viable aerosol producers during the uncovered cough maneuver using an arbitrary pre-defined total CFU of $\geq 10$ or $<10$, respectively, accumulated across the six-stages of the Andersen Impactor (Figure 1). 
The Mann-Whitney U test was used to examine change in mask weight. McNemar's test was used for matched pairs to compare comfort scores for the two mask types.

\section{RESULTS}

Participant overview: Twenty-five (15 male) adult participants with a mean (SD) age of 31.3 (7.8) years, $\mathrm{FEV}_{1} 50.7$ (17.4) \% predicted and BMI $22.1(2.8) \mathrm{kg} / \mathrm{m}^{2}$ were recruited (Table 1). Twenty-two (88\%) participants were on maintenance azithromycin. Eleven (44\%) participants were established on chronic inhaled antibiotic therapy (either continuous or cycling alternate month) and the remaining 14 (56\%) participants had been prescribed inhaled antibiotic therapy (less frequently than alternate months) in the 12 months prior to the study. Eleven participants (44\%) had received intravenous antibiotics in the week prior to their study involvement. The mean (SD) age, $\mathrm{FEV}_{1} \%$ predicted and $\mathrm{BMI}$ of patients attending TPCH ACFC in 2015 was 30.7 (9.9) years, $66.7(24.1) \%$ predicted and $23.0(4.2) \mathrm{kg} / \mathrm{m}^{2}$, respectively. In the preceding calendar year, of 282 patients reviewed at TPCH ACFC, $68.4 \%$ had chronic P. aeruginosa infection.

Sputum microbiology: $P$. aeruginosa was cultured from the 24 sputum samples provided at a mean concentration of $6.3 \times 10^{7} \mathrm{CFU} / \mathrm{mL}\left(95 \% \mathrm{CI}, 2.6 \times 10^{7}-15.0 \times 10^{7}\right.$; Table 1$)$. Genotyping identified 12 different $P$. aeruginosa strains, including five common Australian shared strains (11); AUST-01 $(n=6), \operatorname{AUST}-02(n=9)$, AUST-06 $(n=6)$, AUST-07 $(n=3)$, AUST-13 ( $\mathrm{n}=1)$, five other minor shared strains, and two unique strains. Eight participants harbored more than one $P$. aeruginosa strain; two different strains were detected in seven participants, while one participant was infected with three major Australian shared strains (AUST-01, AUST-02 and AUST-06). Other CF pathogens identified in the sputum on the testing day comprised: Stenotrophomonas maltophilia $(\mathrm{n}=3)$, Aspergillus fumigatus $(\mathrm{n}=3)$, 
234 Haemophilus influenzae $(\mathrm{n}=1)$ and Burkholderia cenocepacia $(\mathrm{n}=1)$. Five participants had a

235 history of intermittent Staphylococcus aureus in the 12 months prior to the study but S. aureus was not isolated from sputum of participants on the day of testing.

\section{Aerosol sampling:}

238 Uncovered cough maneuver. Of the 25 participants, 19 (76\%) produced aerosols containing viable $P$. aeruginosa in the uncovered cough maneuver at 2-meters (Table 2). The participant unable to produce a sputum sample, was one of the six who did not culture $P$. aeruginosa on the cough aerosol plates. Molecular typing revealed that for 16 individuals, the $P$. aeruginosa genotype(s) detected in the individual's cough aerosols were genetically indistinguishable to those isolated in their matched sputum sample. Three other participants (two with one indistinguishable $P$. aeruginosa genotype in their matched aerosol/sputum combination; one with two indistinguishable $P$. aeruginosa strains in their matched aerosol/sputum combination) were each found to have one additional $P$. aeruginosa strain in their aerosol cultures that was not detected in their sputum. The three participants who had isolated $S$. maltophilia in their sputum also generated aerosols that grew this organism (confirmed by MALDI-TOF).

When the total $P$. aeruginosa CFUs of uncovered cough aerosols was associated with demographic, clinical and microbiology parameters, a statistically significant correlation was identified only between log transformed sputum $P$. aeruginosa counts and total aerosol load $(\mathrm{r}=0.55, p=0.01)$. The mean $(\mathrm{SD})$ percentage of culturable particles within the respirable size range ( $\leq 4.7 \mu \mathrm{m}$, collected on Andersen stages 3 to 6$)$ were $71 \%$ (27) in the uncovered cough maneuver and $86 \%(30)$ in the cough etiquette maneuver $(p=0.21)$. 
Talk maneuvers. No aerosol CFUs were recovered from either talk maneuvers for 23/24

257

258

259

260

261

262

263

264

265

266

267

268

269

270

271

272

273

274

275

276

277

278

279

(96\%) participants and a single aerosol P. aeruginosa CFU was cultured from the remaining two participants (one masked and one unmasked study; Table 2).

Face masks and cough etiquette maneuvers. Of the 19 participants that produced culture positive aerosols during uncovered coughing, two (11\%) produced P. aeruginosa positive aerosols wearing the surgical mask, and four (21\%) grew P. aeruginosa in their aerosol cultures when wearing the N95 mask (Table 2). In contrast, $68 \%$ of these participants $(n=13)$ grew $P$. aeruginosa in their aerosols using cough etiquette (Table 2).

High viable aerosol production (total CFUs $\geq 10$ ) was observed in 14/19 (74\%) participants who cultured at least one $\mathrm{CFU}$ in the uncovered cough maneuver. In these participants a reduction in aerosol P. aeruginosa concentration (log CFU) was demonstrated with each strategy designed to interrupt aerosol dispersal: surgical mask (-94\%); N95 mask (-94\%); cough etiquette $(-53 \%)$. The surgical mask $(p<0.001)$ and the N95 mask $(p<0.001)$ were both effective in reducing infectious airborne dispersal compared to uncovered coughing, with cough etiquette providing less reduction in mean P. aeruginosa CFUs than both masks (Table $3)$.

Tolerability of the masks during cough maneuvers varied, with 13 (54\%) participants providing a higher comfort rating to the surgical mask than the N95 mask, compared with two $(8 \%)$ who provided a higher comfort rating to the N95 mask and nine (38\%) who had no preference $(p=0.013)$ (Table 4). Key comments regarding the masks by the participants included: a perceived restriction to or reduction in ease of breathing ( $\mathrm{n}=15,[\mathrm{~N} 95=12])$, sensation of heat $(n=9,[N 95=6])$, sensation of dampness $(n=3$, all surgical $)$ and rubbing/pressure from the mask during coughing $(n=2,[N 95=1])$. There was a similar change in weight of the surgical mask and the N95 mask (median (interquartile range) of 0.01 (0.00- 
$0.02)$ grams and $0.02(0.00-0.04)$ grams, respectively; $p=0.23)$. Cough numbers for each

281

282

283

maneuver were similar and there was no difference in the number of coughs during the N95 mask $(p=0.15)$ and cough etiquette $(p=0.52)$ tests compared to the uncovered coughing intervention (Table S1), indicating that fatigue or participant motivation were unlikely to have impacted the accuracy of the maneuvers.

Infection Control: P. aeruginosa or other CF pathogens were not cultured from blank aerosol tests or surface swabs of the tunnel.

Adverse events: Overall, the maneuvers were well tolerated; however, one participant (listed for lung transplant and $\mathrm{FEV}_{1} 32.5 \%$ predicted) discontinued the N95 mask study due to claustrophobia and increased dyspnoea after mask application.

\section{DISCUSSION}

This study demonstrates that at 2-meters from source, both surgical and N95 masks are highly effective in reducing aerosols containing viable $P$. aeruginosa in the droplet nuclei size range during voluntary coughing in people with CF. Our study uses a system that mimics a hospital environment and has several strengths; it was designed to reflect real-world occurrences by using a model that allows determination of air contamination at the recommended separation distance between people with $\mathrm{CF}$ and by investigating the effect of cough etiquette and two commonly available masks in hospitals on aerosol dispersal. The cough maneuvers examined may also closely replicate aerosol production during airway clearance sessions and spirometry procedures. Furthermore, we provide much-needed information on the short-term tolerability of mask wearing by persons with lung disease, which is an often-overlooked dimension of infection control. 
Cross-infection between people with CF has increasingly been reported over the past two decades, initially with Burkholderia cepacia complex (30, 31), P. aeruginosa (9-11) and more recently Mycobacterium abscessus (15, 32). Progressive changes to infection control policies have been implemented including cohort segregation and changes to practice for patients with $\mathrm{CF}$ in the clinic and inpatient facility. Airborne transmission of $\mathrm{CF}$ pathogens in aerosol droplet nuclei has been suggested and such evidence has contributed to the enhanced rigor of these policies $(17,18)$. Increased separation distance between people with CF and the wearing of surgical masks during hospital visits are now recommended (21). Evidence to support the effectiveness of the latter strategy has been limited. Two previous studies evaluated the effect of surgical mask wearing on bioaerosol spread within a CF cohort. Our finding of a strong protective effect with surgical masks during cough maneuvers corroborate with and strengthen those of Driessche et al. who demonstrated an $86 \%$ reduction in environmental detection of airborne $P$. aeruginosa concentration during mask wearing compared to the reference (coughing without a surgical mask) in a controlled laboratory model (33). In contrast, Zuckerman and colleagues found no difference in rates of air contamination of outpatient exam rooms between mask wearing and unmasked patients with $\mathrm{CF}$, although the overall positive air sample yield was low, including in the control group without mask (0.7\%) (34).

Three quarters of the participants that were studied produced aerosols containing viable $P$. aeruginosa at 2-meters during uncovered coughing. The only predictor of expired aerosol containing viable bacteria was the sputum load of $P$. aeruginosa, which agrees with the results of our earlier work (20), further suggesting burden of infection is a very important determinant of potential infectiousness. A previous study using artificially generated aerosols demonstrated that $P$. aeruginosa respiratory samples with a mucoid phenotype exhibited 
improved survival, although this advantage did not extend to epidemic strains (35). The aerosol samples from the uncovered cough maneuvers in our study revealed both unique and shared Australian strains of $P$. aeruginosa, but the overall numbers were too small to make any conclusions regarding survival characteristics.

To date, very few studies have directly compared the performance of various respiratory hygiene strategies in vivo and to our knowledge, this study is the first that investigates the outward protective effects of various interventions in a $\mathrm{CF}$ population with chronic $P$. aeruginosa infection. We demonstrated that surgical and N95 masks both significantly reduce the potential for bioaerosol dispersal with $>90 \%$ reduction in the mean total CFUs. Previous evidence suggested that impaction of microbe-laden droplets directly onto an obstruction such as a hand or surgical mask during coughing limits the formation of airborne droplet nuclei (36); our findings support this suggestion. Likewise, an earlier study also found that surgical and N95 masks were equally effective in interrupting aerosol transmission of influenza in nine patients (37). A different study considered the impact of cough etiquette strategies (including the hand, a tissue, an arm) on preventing cough aerosols in healthy volunteers (38). Similar to our findings, they reported that the expelled cough aerosol was not completely blocked by cough etiquette, therefore posing a potential risk for airborne transmission (38). Importantly, the majority of viable aerosol detected during uncovered coughing in the current study was in the respirable size range $(<4.7 \mathrm{um})$ and this was not significantly different for the cough etiquette maneuver.

Our study also demonstrates that talking is a low infectious-aerosol producing activity, potentially indicating that the implementation of mask policies for people with CF within the hospital should especially target relevant high risk clinical settings. During times of known high aerosol producing activities (performing spirometry and airway clearance) in the clinical 
setting when a mask is not be feasible, then other considerations such as high air exchange rates, negative pressure rooms and/or adequate washout time periods between patients in individual rooms is important.

354 Although short mask wear duration was overall well tolerated by people with $\mathrm{CF}$, it was perceived as being less comfortable when compared with no mask for the participant, particularly the N95 mask where additional outward protection was not observed. This may be an important factor when considering adherence to correct wearing technique, especially over extended periods. In healthy subjects and healthcare professionals, the use of face masks has been associated with increased breathing resistance (39), headaches (40), and physical discomfort (41, 42), and tolerability lessens with increased duration of wear (43). Furthermore, the physiological effects and comfort of mask wear amongst people with respiratory conditions has not been studied extensively and may have adverse impact. One study that compared surgical and N95 mask efficacy in patients with confirmed influenza reported that one participant (from a cohort of 10) was unable to complete the short protocol due to respiratory distress (37). However, Dharmadhikari and colleagues investigated the clinical efficacy of surgical masks over extended periods in patients with multi-drug resistant tuberculosis and demonstrated a 56\% reduction in transmission risk. Patients wore surgical masks for up to 12-hours duration, with permitted interruptions for meals and medication, although it was reported that patients with respiratory distress were not enrolled into the study and incentives were used to encourage adherence (44). The tolerability of mask wear in people with respiratory infection and lung disease is an area that requires further 372 investigation.

373 High rates of mask interference by the wearer have been reported in people with CF in the outpatient setting (34). In our study, the participants were unable to touch or readjust the 
masks during the testing period, as the arms were positioned outside of the tunnel. However, mask movement and slippage during the coughing maneuvers were observed for some participants. In fact, it was noted that three of the four participants who had detectable $P$. aeruginosa CFUs in the N95 mask cough maneuver experienced mask movement, which may have led to an ineffective facial seal and contributed to the release of viable aerosol.

The participants in this study comprised an adult cohort with moderate to severe lung disease. Based on earlier data demonstrating a strong correlation between $P$. aeruginosa sputum density and cough aerosol concentration $(18,20)$, sputum-producing participants were enrolled as a robust means of assessing mask efficacy within the clinical setting. Our results, nevertheless, highlight the need for additional studies to determine the role and effectiveness of masks in $\mathrm{CF}$ pediatric populations, or for those with preserved lung function and/or those who rarely expectorate sputum. Despite this, there are some important caveats to consider: i) one participant in the current study did not produce a sputum sample and importantly, was one of the six participants who did not culture P. aeruginosa in their cough aerosol. However, our earlier data demonstrates non-productive patients can produce viable aerosols $(18,20)$; ii) quantitative sputum microbiology is not routinely performed in most CF Centers serviced by clinical microbiology laboratories; iii) other clinical parameters do not predict viable aerosol production $(18,20)$ and iv) the infective inoculum of $P$. aeruginosa (or other CF pathogens) is not known and therefore we cannot estimate the extent of infection risk for an individual following single (or for that matter multiple) exposure episodes to cough aerosols. Taken together, we suggest that a universal mask wearing approach across both adult and pediatric CF Centers should be strongly considered to mitigate the risk of person-to-person spread of CF pathogens. 
Limitations of our study include that the application and check of mask fit by a health care professional and the short mask wearing duration of less than 10-minutes may not reflect the typical application in a clinical setting; therefore the study may overestimate the protective effect of face masks. Furthermore, the cough etiquette technique adopted by participants differed widely, which may impact the results but does allow a more real-world situation. The culture media used in the Andersen Cascade Impactors and incubation conditions were selective for non-fastidious, aerobic gram-negative bacteria and did not allow the investigation of cough aerosol viability of other $\mathrm{CF}$ pathogens such as $H$. influenzae, Staphylococcus aureus and non-tuberculous mycobacteria. Whilst we focused specifically on P. aeruginosa in this study, our earlier work has demonstrated similar findings of viable aerosols of common CF pathogens $(18,20)$, thus it is likely that the effectiveness of masks would generalize to other bacteria in people with CF. Finally, compared to the clinically stable patients, we observed a greater proportion of participants receiving intravenous antibiotics for pulmonary exacerbations that were low viable aerosol producers. However, the current study was not powered to examine the impact of clinical status (clinical stability versus pulmonary exacerbation) and antimicrobial therapies on viable aerosol production.

414 Further studies are required to address this clinically important question.

415 In conclusion, masks are a simple and relatively inexpensive method to effectively interrupt aerosol dispersal of $P$. aeruginosa in droplet nuclei generated during coughing in people with

$417 \mathrm{CF}$, with the surgical mask providing enhanced wearer comfort. These data support the USA CFF Infection Prevention and Control Guidelines for individuals with CF to wear a surgical mask to reduce environmental contamination and potential viable aerosol spread associated 420 with coughing in communal areas of health facilities (21). Cough etiquette reduces viable bacterial aerosols, but not to the same extent as masks. Future studies will assess whether 
423 wearer tolerability and mask effectiveness.

424

\section{ACKNOWLEDGEMENTS}

426 We express our gratitude to the study participants and to the ACFC team members who

427 supported the project, including Andrea Beevers, Janice Geary and the Infection Control 428 nursing team at The Prince Charles Hospital. 


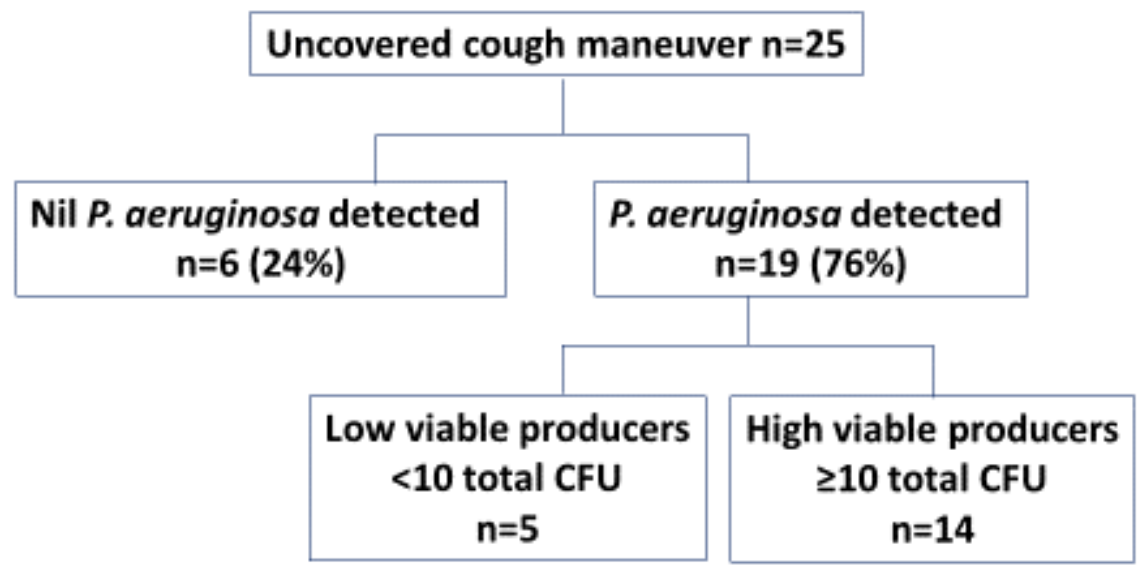

430

431 Figure 1. Results of the uncovered cough (reference) maneuver 
Table 1. Baseline demographic and clinical characteristics of the study participants

Participant Characteristics

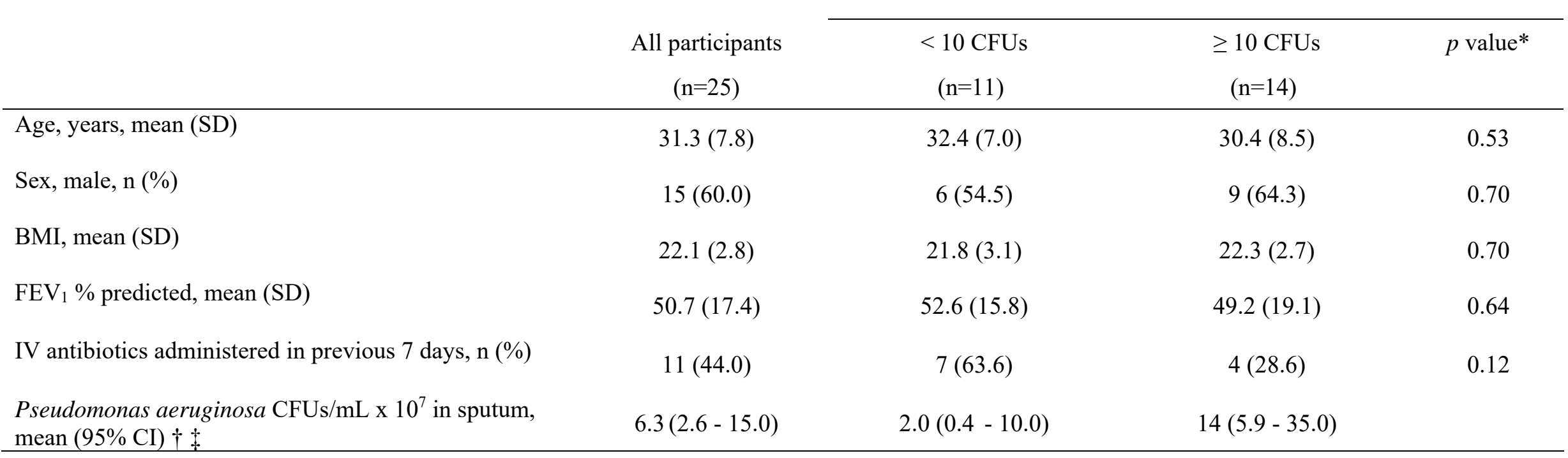

*Pairwise comparison between participants with $<10$ (including nil) and $\geq 10$ viable $P$. aeruginosa aerosol CFUs

$\uparrow$ A sputum sample was provided by $24 / 25$ participants

†alue is geometric mean

Definition of abbreviations: BMI, body mass index; $\mathrm{FEV}_{1}$, forced expiratory volume in $1 \mathrm{sec}$; IV, intravenous; CFU, colony forming unit; CI, confidence interval 
Table 2. Number of participants with detectable aerosol $P$. aeruginosa colony forming unit (CFU) counts across each study maneuver*

\begin{tabular}{|c|c|c|c|}
\hline \multirow[t]{2}{*}{ Maneuver } & \multirow[t]{2}{*}{$\begin{array}{l}\text { Participants with } \\
\text { detectable } \\
\text { P. aeruginosa CFUs, } \\
\text { n (\%) }\end{array}$} & \multicolumn{2}{|c|}{$\begin{array}{l}\text { Stratification of participants with detectable } \\
\text { P. aeruginosa CFUs into high and low viable } \\
\text { aerosol production }\end{array}$} \\
\hline & & $<10^{*}$ & $\geq 10^{*}$ \\
\hline Uncovered coughing (Reference) & $19 / 25(76.0)$ & $5 / 5$ & $14 / 14$ \\
\hline Talking $\dagger$ & $1 / 24(4.2)$ & $0 / 5$ & $1 / 13$ \\
\hline Talking wearing a surgical mask $\dagger$ & $1 / 24(4.2)$ & $0 / 5$ & $1 / 13$ \\
\hline Coughing wearing a surgical mask & $2 / 25(8.0)$ & $0 / 5$ & $2 / 14$ \\
\hline Coughing wearing an N95 mask & $4 / 24(16.7)$ & $1 / 5$ & $3 / 14$ \\
\hline Cough etiquette & $13 / 25(52.0)$ & $2 / 5$ & $11 / 14$ \\
\hline
\end{tabular}

442

*Participants were stratified according to a pre-defined definition of high ( $\geq 10 \mathrm{CFU})$ and low $(<10 \mathrm{CFU})$ viable aerosol production of detectable 444 P. aeruginosa CFU during the uncovered cough maneuver.

$445 \dagger$ One participant did not complete the maneuver (insufficient culture media available)

$446 \ddagger$ One participant did not complete the maneuver (due to adverse event)

447 Definition of abbreviations: CFUs, colony forming units 
448 Table 3. Pseudomonas aeruginosa total colony-forming unit (CFU) counts for each of the 449 maneuvers compared to uncovered coughing (reference) for the high viable aerosol producers $450 \quad(n=14)$

451

\begin{tabular}{lcc}
\hline Maneuver & $\begin{array}{c}\log _{10} P . \text { aeruginosa CFUs } \\
\text { mean }(95 \% \mathrm{CI})\end{array}$ & $p$ value \\
\hline Uncovered coughing (reference) & $1.66(1.41-1.91)$ & - \\
Talking* & $0.02(0.00-0.07)$ & $<0.001$ \\
Talking wearing a surgical mask* & $0.02(0.00-0.07)$ & $<0.001$ \\
Coughing wearing a surgical mask & $0.11(0.00-0.32)$ & $<0.001$ \\
Coughing wearing an N95 mask $\dagger$ & $0.13(0.00-0.30)$ & $<0.001$ \\
Cough etiquette & $0.90(0.50-1.30)$ & \\
\hline
\end{tabular}

452

$453 *$ One participant did not complete the maneuver (insufficient culture media available)

$454 \dagger$ One participant did not complete the maneuver (due to adverse event)

455 Definition of abbreviations: CI, confidence interval; CFUs, colony forming units 
457 Table 4. A matched pairs comparison of the comfort levels during cough maneuvers while 458 wearing the surgical mask and the N95 mask $(n=24) *$

460

461

462

463

464

465

466

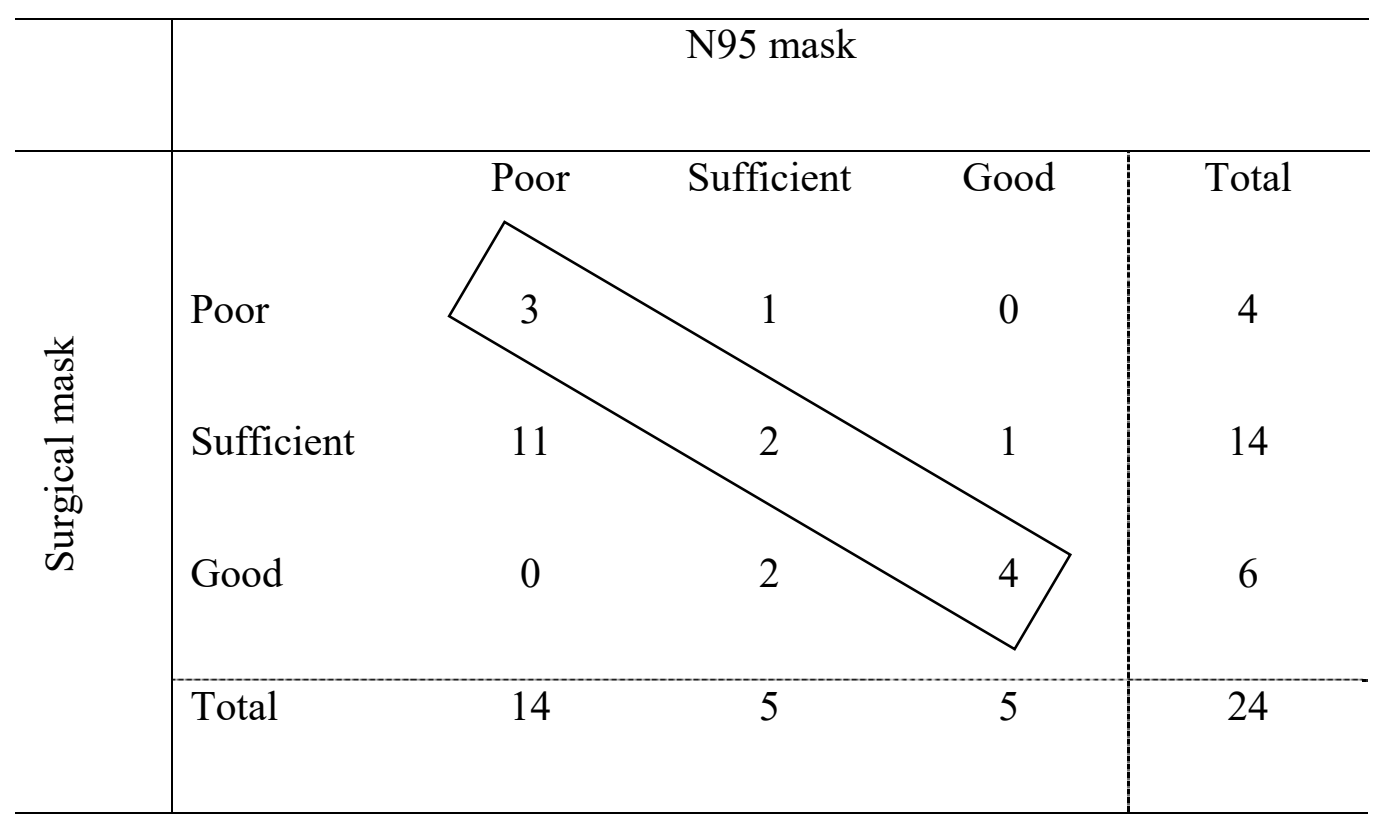

467

468 * Comfort level categories: a) very poor, b) poor, c) sufficient, d) good, e) very good. A low

469 number of responses were obtained in the a) very poor and e) very good categories; therefore,

470 for the analysis, the categories of a) very poor and b) poor were combined ("poor"), as were

471 the categories of d) good and e) very good (“good").

472 The boxed area represents participants $(n=9)$ who reported no preference for the comfort of 473 the surgical mask or the N95 mask. Numbers to the right of the boxed area represent 474 participants $(n=2)$ who provided a higher comfort rating to the N95 mask and those to the left 475 represent participants $(n=13)$ who provided a higher comfort rating to the surgical mask. 
REFERENCES

477 1. Cystic Fibrosis Australia. Cystic fibrosis in Australia 2014. 17th Annual Report from the Australian Cystic Fibrosis Data Registry. 2016 [cited 201715 July ]. Available from: www.cysticfibrosis.org.au.

2. Cystic Fibrosis Foundation. Cystic Fibrosis Patient Registry: 2015 Annual Data Report. 2016 [cited 201715 July]. Available from: https:/www.cff.org/Our-Research/CFPatient-Registry/2015-Patient-Registry-Annual-Data-Report.

3. Ramsay KA, Sandhu H, Geake JB, Ballard E, O'Rourke P, Wainwright CE, Reid DW, Kidd TJ, Bell SC. The changing prevalence of pulmonary infection in adults with cystic fibrosis: A longitudinal analysis. J Cyst Fibros 2016.

4. Emerson J, Rosenfeld M, McNamara S, Ramsey B, Gibson RL. Pseudomonas aeruginosa and other predictors of mortality and morbidity in young children with cystic fibrosis. Pediatr Pulmonol 2002; 34: 91-100.

5. Kosorok MR, Zeng L, West SE, Rock MJ, Splaingard ML, Laxova A, Green CG, Collins J, Farrell PM. Acceleration of lung disease in children with cystic fibrosis after Pseudomonas aeruginosa acquisition. Pediatr Pulmonol 2001; 32: 277-287.

6. Nixon GM, Armstrong DS, Carzino R, Carlin JB, Olinsky A, Robertson CF, Grimwood K. Clinical outcome after early Pseudomonas aeruginosa infection in cystic fibrosis. $J$ Pediatr 2001; 138: 699-704.

7. Aaron SD, Vandemheen KL, Ramotar K, Giesbrecht-Lewis T, Tullis E, Freitag A, Paterson N, Jackson M, Lougheed MD, Dowson C, Kumar V, Ferris W, Chan F, Doucette S, Fergusson D. Infection with transmissible strains of Pseudomonas aeruginosa and clinical outcomes in adults with cystic fibrosis. JAMA 2010; 304: 2145-2153. 
500

501

502

503

504

505

506

507

508

509

510

511

512

513

514

515

516

517

518

519

520

521

522

523

8. Armstrong DS, Nixon GM, Carzino R, Bigham A, Carlin JB, Robins-Browne RM, Grimwood K. Detection of a widespread clone of Pseudomonas aeruginosa in a pediatric cystic fibrosis clinic. Am J Respir Crit Care Med 2002; 166: 983-987.

9. Cheng K, Smyth RL, Govan JRW, Doherty C, Winstanley C, Denning N, Heaf DP, van Saene H, Hart CA. Spread of $\beta$-lactam-resistant Pseudomonas aeruginosa in a cystic fibrosis clinic. The Lancet 1996; 348: 639-642.

10. Jones AM, Govan JR, Doherty CJ, Dodd ME, Isalska BJ, Stanbridge TN, Webb AK. Spread of a multiresistant strain of Pseudomonas aeruginosa in an adult cystic fibrosis clinic. Lancet 2001; 358: 557-558.

11. Kidd TJ, Ramsay KA, Hu H, Marks GB, Wainwright CE, Bye PT, Elkins MR, Robinson PJ, Rose BR, Wilson JW, Grimwood K, Bell SC. Shared Pseudomonas aeruginosa genotypes are common in Australian cystic fibrosis centres. Eur Respir J 2013; 41: 1091-1100.

12. Saiman L, Siegel J, Cystic Fibrosis Foundation Consensus Conference on Infection Control Participants. Infection control recommendations for patients with cystic fibrosis: Microbiology, important pathogens, and infection control practices to prevent patient-to-patient transmission. American Journal of Infection Control 2003; 31: S1-62.

13. Griffiths AL, Jamsen K, Carlin JB, Grimwood K, Carzino R, Robinson PJ, Massie J, Armstrong DS. Effects of segregation on an epidemic Pseudomonas aeruginosa strain in a cystic fibrosis clinic. Am J Respir Crit Care Med 2005; 171: 1020-1025.

14. France MW, Dodd ME, Govan JR, Doherty CJ, Webb AK, Jones AM. The changing epidemiology of Burkholderia species infection at an adult cystic fibrosis centre. $J$ Cyst Fibros 2008; 7: 368-372. 
15. Bryant JM, Grogono DM, Rodriguez-Rincon D, Everall I, Brown KP, Moreno P, Verma D, Hill E, Drijkoningen J, Gilligan P, Esther CR, Noone PG, Giddings O, Bell SC, Thomson R, Wainwright CE, Coulter C, Pandey S, Wood ME, Stockwell RE, Ramsay KA, Sherrard LJ, Kidd TJ, Jabbour N, Johnson GR, Knibbs LD, Morawska L, Sly PD, Jones A, Bilton D, Laurenson I, Ruddy M, Bourke S, Bowler IC, Chapman SJ, Clayton A, Cullen M, Dempsey O, Denton M, Desai M, Drew RJ, Edenborough F, Evans J, Folb J, Daniels T, Humphrey H, Isalska B, Jensen-Fangel S, Jonsson B, Jones AM, Katzenstein TL, Lillebaek T, MacGregor G, Mayell S, Millar M, Modha D, Nash EF, O'Brien C, O'Brien D, Ohri C, Pao CS, Peckham D, Perrin F, Perry A, Pressler T, Prtak L, Qvist T, Robb A, Rodgers H, Schaffer K, Shafi N, van Ingen J, Walshaw M, Watson D, West N, Whitehouse J, Haworth CS, Harris SR, Ordway D, Parkhill J, Floto RA. Emergence and spread of a human-transmissible multidrugresistant nontuberculous mycobacterium. Science 2016; 354: 751-757.

16. Ridderberg W, Wang M, Norskov-Lauritsen N. Multilocus sequence analysis of isolates of Achromobacter from patients with cystic fibrosis reveals infecting species other than Achromobacter xylosoxidans. J Clin Microbiol 2012; 50: 2688-2694.

17. Jones AM, Govan JR, Doherty CJ, Dodd ME, Isalska BJ, Stanbridge TN, Webb AK. Identification of airborne dissemination of epidemic multiresistant strains of Pseudomonas aeruginosa at a CF centre during a cross infection outbreak. Thorax 2003; 58: 525-527.

18. Wainwright CE, France MW, O'Rourke P, Anuj S, Kidd TJ, Nissen MD, Sloots TP, Coulter C, Ristovski Z, Hargreaves M, Rose BR, Harbour C, Bell SC, Fennelly KP. Cough-generated aerosols of Pseudomonas aeruginosa and other Gram-negative bacteria from patients with cystic fibrosis. Thorax 2009; 64: 926-931. 
19. World Health Organization. Infection prevention and control of epidemic and pandemic prone acute respiratory disease in health care. 2014 [cited 20179 July ]. Available from: http://www.who.int/csr/bioriskreduction/infection_control/publication/en/.

20. Knibbs LD, Johnson GR, Kidd TJ, Cheney J, Grimwood K, Kattenbelt JA, O'Rourke PK, Ramsay KA, Sly PD, Wainwright CE, Wood ME, Morawska L, Bell SC. Viability of Pseudomonas aeruginosa in cough aerosols generated by persons with cystic fibrosis. Thorax 2014; 69: 740-745.

21. Saiman L, Siegel JD, LiPuma JJ, Brown RF, Bryson EA, Chambers MJ, Downer VS, Fliege J, Hazle LA, Jain M, Marshall BC, O'Malley C, Pattee SR, Potter-Bynoe G, Reid S, Robinson KA, Sabadosa KA, Schmidt HJ, Tullis E, Webber J, Weber DJ, Cystic Fibrous F, Society for Healthcare Epidemiology of America. Infection prevention and control guideline for cystic fibrosis: 2013 update. Infection Control and Hospital Epidemiology 2014; 35 Suppl 1: S1-S67.

22. Patel RB, Skaria SD, Mansour MM, Smaldone GC. Respiratory source control using a surgical mask: An in vitro study. Journal of Occupational and Environmental Hygiene 2016; 13: 569-576.

23. Wood ME, Stockwell RE, Johnson GR, Ramsay KA, Sherrard LJ, Jabbour N, Knibbs LD, Kidd TJ, Wainwright CE, Morawska L, Bell SC. Face masks and cough etiquette reduce cough-generated bioaerosols containing Pseudomonas aeruginosa in patients with cystic fibrosis. Pediatric Pulmonology 2016; 51(S45): S308.

24. Johnson GR, Knibbs LD, Kidd TJ, Wainwright CE, Wood ME, Ramsay KA, Bell SC, Morawska L. A Novel Method and Its Application to Measuring Pathogen Decay in Bioaerosols from Patients with Respiratory Disease. PloS one 2016; 11: e0158763.

25. Driessche KV, Marais BJ, Wattenberg M, Magis-Escurra C, Reijers M, Tuinman IL, Boeree MJ, Van Soolingen D, de Groot R, Cotton MF. The Cough Cylinder: a tool to 

study measures against airborne spread of (myco-) bacteria. Int J Tuberc Lung Dis 2013; 17: 46-53.

26. Gregoretti C, Confalonieri M, Navalesi P, Squadrone V, Frigerio P, Beltrame F, Carbone G, Conti G, Gamna F, Nava S, Calderini E, Skrobik Y, Antonelli M. Evaluation of patient skin breakdown and comfort with a new face mask for non-invasive ventilation: a multi-center study. Intensive Care Medicine 2002; 28: 278-284.

27. Miller MR, Hankinson J, Brusasco V, Burgos F, Casaburi R, Coates A, Crapo R, Enright P, van der Grinten CP, Gustafsson P, Jensen R, Johnson DC, MacIntyre N, McKay R, Navajas D, Pedersen OF, Pellegrino R, Viegi G, Wanger J, Force AET. Standardisation of spirometry. Eur Respir J 2005; 26: 319-338.

28. Stanojevic S, Wade A, Stocks J, Hankinson J, Coates AL, Pan H, Rosenthal M, Corey M, Lebecque P, Cole TJ. Reference ranges for spirometry across all ages: a new approach. Am J Respir Crit Care Med 2008; 177: 253-260.

29. Syrmis MW, Kidd TJ, Moser RJ, Ramsay KA, Gibson KM, Anuj S, Bell SC, Wainwright CE, Grimwood K, Nissen M, Sloots TP, Whiley DM. A comparison of two informative SNP-based strategies for typing Pseudomonas aeruginosa isolates from patients with cystic fibrosis. BMC Infect Dis 2014; 14: 307.

30. Govan JR, Brown PH, Maddison J, Doherty CJ, Nelson JW, Dodd M, Greening AP, Webb AK. Evidence for transmission of Pseudomonas cepacia by social contact in cystic fibrosis. Lancet 1993; 342: 15-19.

31. LiPuma JJ, Dasen SE, Nielson DW, Stern RC, Stull TL. Person-to-person transmission of Pseudomonas cepacia between patients with cystic fibrosis. Lancet 1990; 336: 10941096.

32. Bryant JM, Grogono DM, Greaves D, Foweraker J, Roddick I, Inns T, Reacher M, Haworth CS, Curran MD, Harris SR, Peacock SJ, Parkhill J, Floto RA. Whole- 
genome sequencing to identify transmission of Mycobacterium abscessus between patients with cystic fibrosis: a retrospective cohort study. Lancet 2013; 381: 15511560.

33. Driessche KV, Hens N, Tilley P, Quon BS, Chilvers MA, de Groot R, Cotton MF, Marais BJ, Speert DP, Zlosnik JE. Surgical Masks Reduce Airborne Spread of Pseudomonas aeruginosa in Colonized Patients with Cystic Fibrosis. Am J Respir Crit Care Med 2015; 192: 897-899.

34. Zuckerman JB, Clock SA, Prato BS, McDevitt JJ, Zhou JJ, Leclair LW, Lucas FL, Saiman L. Air contamination with bacteria in cystic fibrosis clinics: implications for prevention strategies. Am J Respir Crit Care Med 2015; 191: 598-601.

35. Clifton IJ, Fletcher LA, Beggs CB, Denton M, Peckham DG. A laminar flow model of aerosol survival of epidemic and non-epidemic strains of Pseudomonas aeruginosa isolated from people with cystic fibrosis. BMC Microbiology 2008; 8: 105.

36. Riley RL. Airborne infection. The American Journal of Medicine 1974; 57: 466-475.

37. Johnson DF, Druce JD, Birch C, Grayson ML. A quantitative assessment of the efficacy of surgical and N95 masks to filter influenza virus in patients with acute influenza infection. Clin Infect Dis 2009; 49: 275-277.

38. Zayas G, Chiang MC, Wong E, MacDonald F, Lange CF, Senthilselvan A, King M. Effectiveness of cough etiquette maneuvers in disrupting the chain of transmission of infectious respiratory diseases. BMC Public Health 2013; 13: 811.

39. Lee HP, Wang de Y. Objective assessment of increase in breathing resistance of N95 respirators on human subjects. The Annals of Occupational Hygiene 2011; 55: $917-$ 921. 
40. Lim EC, Seet RC, Lee KH, Wilder-Smith EP, Chuah BY, Ong BK. Headaches and the N95 face-mask amongst healthcare providers. Acta Neurologica Scandinavica 2006; 113: 199-202.

41. Radonovich LJ, Jr., Cheng J, Shenal BV, Hodgson M, Bender BS. Respirator tolerance in health care workers. JAMA 2009; 301: 36-38.

42. MacIntyre CR, Cauchemez S, Dwyer DE, Seale H, Cheung P, Browne G, Fasher M, Wood J, Gao Z, Booy R, Ferguson N. Face mask use and control of respiratory virus transmission in households. Emerg Infect Dis 2009; 15: 233-241.

43. Shenal BV, Radonovich LJ, Jr., Cheng J, Hodgson M, Bender BS. Discomfort and exertion associated with prolonged wear of respiratory protection in a health care setting. Journal of Occupational and Environmental Hygiene 2012; 9: 59-64.

44. Dharmadhikari AS, Mphahlele M, Stoltz A, Venter K, Mathebula R, Masotla T, Lubbe W, Pagano M, First M, Jensen PA, van der Walt M, Nardell EA. Surgical face masks worn by patients with multidrug-resistant tuberculosis: impact on infectivity of air on a hospital ward. Am J Respir Crit Care Med 2012; 185: 1104-1109. 